\title{
Geçmişten Günümüze İngiltere Sağlık Politikaları: Ulusal Sağlık Sistemi Odaklı Güncel Bir Perspektif ${ }^{1}$
}

\author{
DOI: 10.26466/opus.548218 \\ *
}

\section{Erdal Eke* - Merve Kişi**}

*Dr. Öğr,Süleyman Demirel Üniversitesi, İỉBF, Sağlık Yönetimi Bölümü, Isparta/Türkiye

E-Posta: erdaleke@sdu.edu.tr

ORCID: 0000-0002-9529-5889

**Arş. Gör.,Süleyman Demirel Üniversitesi, İ̈BF, Sağlık Yönetimi Bölümü, Isparta/Türkiye

E-Posta: merveuysal@sdu.edu.tr

ORCID: $\underline{0000-0001-9226-8490}$

\section{Öz}

İngiltere, geçmişten günümüze siyasi ve ekonomik göstergeler açısından olduğu kadar sağhlk politikaları ve uygulamaları açısından da dünyada önemli bir yere sahiptir. Beveridge ve Ulusal Sağlık Sistemi kavramlarıyla sembolize edilen İngiltere sağllk politikaları, diğer ülkelerde olduğu gibi kronolojik olarak bir değişim yaşamıştır. Özellikle Brexit süreciyle birlikte İngiltere önemli bir aşamaya gelmiş, bu aşamanın olumlu ve olmumsuz yönleri olduğuna dair literatürde çeşitli görüşler mevcuttur. Çalışmanın amacı, Ulusal Sağlık Sistemi öncesi ve sonrası İngiltere sağlık politikalarının betimlemesini yapmaktır. Kavramsal bir yapıda kurgulanan çalışmanın kapsamında, kurulduğu günden günümüze Ulusal Sağlık Sistemi'nin yapısal özellikleri ve geçirdiği yasal ve yönetimsel değişiklikler yer almaktadır. Çalı̧̧ma sonucunda 1948'den günümüze siyasal iktidarlarn programlar ve küresel ekonomik gelişmelere bağlı olarak Ingiltere'de sağlık politikalarının değişim gösterdiği; Ulusal Sağllk Sistemi kapsamında bireylerin sağlık hizmetleri maliyetlerinin ağırlıkl olarak vergilerden karşılandığı; ve bu durumun hükümet nezdinde sürekli bir tartışma alanı olduğu ve son yıllarda Ulusal Sağlık Sisteminin yapısal ve işlevsel sorunlar yaşadığı başta olmak üzere çeşitli bulgulara ulaşılmıştır.

Anahtar Kelimeler: Sağlık Politikaları,Sağlık Sistemi,Ulusal Sağlık Sistemi, İngiltere Sağlık Sistemi.

\footnotetext{
${ }^{1}$ Bu makale 11-13 Ekim 2018 tarihinde düzenlenen 2. Uluslararası 12. Ulusal Sağlık ve Hastane idaresi Kongresi'nde sunulan "ingiltere Sağlık Politikaları Özelinde Güncel Bir Perspektif" başlıklı bildirinin genişletilmiş halidir.
} 


\title{
England Health Policies from Past to Present: A Current Perspective Focused on the National Health System
}

\begin{abstract}
England has an important place in the world in terms of health politics and practices as much as it is in terms of past political and economic indicators. Beveridge and the England health policy, symbolized by the National Health System, are chronologically changing, just like in other countries. Especially with the Brexit process, England has come to an important stage and there are various opinions in the literature that this stage has positive and negative aspects. The aim of the study is to describe the England health policies before and after the National Health System. Within the framework of the conceptual work, from the begining till today National Health System's structural characteristics and legal and managerial changes are introduced. As a result of the study, from 1948 to the present day, health policies in the England were found to change, depending on the political power and global economic developments. Within the National Health System, various findings have been reached, including that the costs of health services for individuals are mainly covered by taxation, which is a constant debate in government, and in recent years the National Health System has experienced structural and functional problems.
\end{abstract}

Keywords Health Politics, Health System,National Health System,England Health System. 


\section{Giriş}

Politika, bir nüfusta belirli bir durumun, olayın ortaya çıkmasını sağlama veya sınırlama şeklinde ilgili bir makam tarafından verilen bir karardır. Sağlık politikası ise sağlığa erişim ile ilgili olarak her türlü etkiyi ve kararları kapsamaktadır. Bu kapsamda sağlık hizmeti sunumu ve sağlayıcıları çerçevesi açısından sağlık politikası, doğrudan veya dolaylı olarak sosyal ve fiziksel ortamları, davranışları, sosyoekonomik durumu ve tıbbi bakım hizmetlerine erişilebilirliği ve ulaşımı etkileyebilecek mevzuat şeklinde tanımlanabilecektir. Bu politikaların oluşumu hem devlet hem de özel sektör kanalıyla olmaktadır (ACHE, s.16-17).

Dünya üzerinde sağlık politikaları her ülkeye özgü olsa da mevcut durumda ülkeler, erken ölümler, zengin-yoksul arasındaki farklılıklar, obezite gibi hala pek çok sağlık sorunu ile mücadele etmektedir. Gelir düzeyi oldukça yüksek olan Batı ülkelerinde de eşitsizlikler artmakta, düşük ve orta gelirli ülkelerde ise yoksulların gelir düzeyi oldukça düşük kalmaktadır (Mooney, Çev. Terzi, 2014, s.23-25).

İngiltere Sağlık Sistemi, vergi temelli olan Beveridge tipi bir sağlık sistemidir. Sir William Beveridge'in, 2. dünya savaşından sonra yeniden sosyal yapılanmayı planlamasıyla, Beveridge, Londra'nın doğu ucundaki yoksullar arasında bir sosyal hizmet görevini üstlenmişti. Hazırlanan raporda eğitim, istihdam, barınma ve sosyal güvenliği teşvik eden savaş sonrası hükümet ana planının bir parçası olarak kapsamlı sağlık hizmeti gündeme gelmiştir (Light, 2003, s.26). Bu amaçla Birleşik Krallık Ulusal Sağlık Hizmeti (NHS) ulusal bir sistem olma amacı ile 1948 yılında kurulmuştur. NHS, İngiltere, İskoçya ve Galler'e benzer şekilde hizmet verirken, Kuzey İrlanda'nın sağlık sistemi yarı otonom olarak çalışmıştır (Cylus et al, 2015, s.14). NHS'nin kurulumundan bu yana İngiltere Sağlık Sistemi çeşitli hükümetlerin politikaları sebebiyle belirli değişimler geçirmiş, bu değişimlerin olumlu ve olumsuz etkileri olmuştur.

1970'lerin sonunda Birleşik Krallık'ta Başkan Thatcher'ın neoliberalizmin İngiltere sağlik sistemine girmesiyle birlikte neoliberalizmin doğasında olan vergilerin düşmesi sağlık sisteminde sadece olumlu etkiler yaratmamıştır (Mooney, Çev. Terzi, 2014, s.23-25).

Genel olarak değerlendirildiğinde İngiltere dünyada sayılı güçlerden olsa da yukarıda belirtildiği gibi pek çok sorunla mücadele etmektedir. 
Neoliberal politikalarla birlikte İngiltere özelleştirmeyi sistemine dahil etmiş, bu da bazı sonuçlara yol açmıştır. Son olarak İngiltere'nin Avrupa Birliği'nden ayrılma süreci sağlık sistemi üzerinde bazı etkilere sebep olmuştur.

\section{Ulusal Sağlık Sistemi (NHS) Öncesi İngiltere Sağlık Sistemi ve Poli- tikaları}

İngiltere, küresel sağlık politikalarının şekillenmesi ve sağlık sistemindeki reform uygulamaları açısından rol model konumundaki ülkelerden birisi olarak gösterilmektedir. Ancak bu konumuna ulaşmasında Ulusal Sağlık Sistemi (National Health Services) olarak bilinen sistemin önemi kabul edilebilir bir gerçektir. Ulusal Sağlık Sistemi'ni doğru betimleyebilmek ve anlayabilmek için bu sisteme geçilmeden önce İngiltere sağlık politika ve uygulamalarının işleyiş̧inden bahsetmek faydalı olacaktır.

NHS öncesi dönemde hem sağlik hizmetlerine ulaşım hem de kalite yönünden pek çok sorunun olması, hastanelerin ücretli olması, ücretsiz sağlık hizmetinin tanınmış olmasına rağmen çok az kişinin faydalanması, ülke içerisinde sağlık sisteminde hizmet sunumu açısından bazı gönüllüleri teşvik etmiştir. NHS öncesi dönemde 19. yüzyılda hayırseverler ve sosyal reformcular, gelir durumu olmayanlara ücretsiz tıbbi hizmet sağlamayı denemişlerdir. 1844 yılında hâlâ Kraliyet Serbest Hastanesi (Royal Free Hospital) olarak hizmet vermeye devam eden bir dispanser kurulmuş, bu kuruluş otuz bin hastaya ücretsiz hizmet sunmuştur. Büyük şehirlerdeki Belediye Hastaneleri (Municipal Hospitals) gibi hastaneler yerel idareler olarak hizmet vermiştir (Sargutan, 2010, s.526).

Bütün bu olumlu gelişmelere rağmen çeşitli olumsuzluklar da söz konusu olmuştur. Örneğin hekime sadece maddi durumu iyi olanlar gidebilmiş, maddiyatı yeterli olmayanlar ise ölüme ya da hastalığa mahkûm edilmiştir. Diğer taraftan ise akıl sağlığı yerinde olmayanlar ise dışlanarak ya da zincirlenerek sağlik hizmetlerinden mahrum bırakılmıştır (Aksakoğlu ve Giray, 2006, s.1).

1911 yılında David Lloyd George, çalışanların ücretinden az miktarda kesilmesi karşılığında ücretsiz sağlık hizmeti alma hakkına sahip olmasını sağlayan Ulusal Sigorta Yasası'nı çıarmıştır. Ancak bu yasa yalnızca istihdam edilen kişilere sağlık hizmeti hakkı vermiştir (Chang vd., 2011). 
Buna rağmen bu durum sağlık politikalarının gelişimi açısından önemli bir adım olarak da değerlendirilebilir.

Genel olarak değerlendirildiğinde İkinci Dünya Savaşı'ndan önce, yaşlı ve fiziksel olarak engeli olan insanlar için yalnızca devlet tarafından finanse edilen sosyal bakım, Yoksullar Yasası (1929 Yerel Yönetimler Yasası'nın ardından Kamu Yardımı olarak adlandırılmıştır) aracılığıyla gerçekleşmiştir. Ortaçağdan beri, yaşlı ve engelli kişilere inanç örgütleri ya da diğer gönüllü kuruluşlar tarafından yönetilen bakım evi desteği sağlanmıştır. Özellikle 19. yüzyılda, hayır kurumları toplumda bakım görevini üstlenmiş, Yoksullar Kanunu ile yerel yetkililerle yoksullara yönelik desteği en üst düzeye çıarmak için işbirliği yapmışlardır (Thander, 2009, s.2-4).

\section{Ulusal Sağlık Sistemi ve İngiltere Sağlık Politikalarının Değişimi}

Ulusal Sağlık Sistemi, İngiltere sağlık sistemi ve politikaları açısından kritik bir reform uygulamasıdır. Ülke içerisindeki sağlık sisteminin işleyişini temelden etkileyen ve değiştiren bir kapsama sahip olan bu sistem, dünyadaki diğer ülkelere de örnek teşkil eden bir politika sürecini beraberinde getirmiştir.

\section{0 Öncesi Dönemde Ulusal Sağlık Sisteminin Genel Özellikleri ve Sağlik Politikaları}

1948 yılında kurulan Ulusal Sağlık Sistemi (NHS), Birleşik Krallık kamu sağlık sektöründen sorumlu olan bir kurumdur. Ulusal Sağlık Sistemi'nden önce, İngiltere'deki sağlık hizmetleri genellikle yalnızca zenginler tarafından kullanılabilmiştir. İkinci Dünya Savaşı'ndan sonra ise ihtiyaç anında ücretsiz hizmetler sağlayan, merkezi vergilerden finanse edilen ve herkesi kapsayan bir kamu sağlık sistemi başlatmak için çalışmalar başlamıştır (Chang vd., 2011). Bu noktadan sonra Birleşik Krallık Sağlık Sistemi vergiyle finanse edilen bir sağlık sistemi olarak karşımıza çıkmıştır. "Beveridge tipi sağlık sistemleri" olarak bilinen vergiye dayalı sağlık sistemi aslında ismini 2. Dünya Savaşı sonrası İngiltere'de sağlık, eğitim gibi hizmetlerin kamusallaştırılmasını, devletin bu 
rolü alması gerektiğini savunan sosyal politikacı William Henry Beveridge'den almaktadır (Dinç, 2009, s.5).

Beveridge'in 'kamusal' modelinde, finansman esas olarak vergilendirmeye dayanmakta ve merkezi olarak organize edilmiş bir Ulusal Sağlık Sistemi (National Health Service) ile hizmetlerin çoğu halk sağlığ hizmeti sunucuları (hastaneler, toplum doktorları, vb.) tarafindan sağlanmaktadır (Lameire vd., 1999, s.5).

Devlet tarafından işletilen kurumlarda evrensel kapsam ile karakterize edilen Ulusal Sağlık Sistemi (NHS) ve zorunlu sigorta İngiltere'de 1948'den beri, Danimarka'da ise 1973'ten beri birinci sistem olarak kullanılmaktadır (Hitiris, 1997,s.2). Bu modelde kapsam konusu vatandaşlardır, herkes gelir, iş, aile gibi durumlara bakılmaksızın kapsam içindedir, finansmanı ise genel vergilerden sağlanmaktadır. Bu modele göre sağlık hizmeti sunumu kamu tarafından sunulmaktadır. Bu sistem içinde çalışan sağlık personeli maaşlı memur statüsündedir (Yıldırım ve Yıldırım, 2011, s.314).

Model üç basamaktan oluşan ve etkili sevk zincirini amaçlayan bir sağlik sistemini içermektedir. Buna göre hizmet sunumu noktasında aile hekimi, kamu hastanesi ve sağlık ocağ 1 etkin olmakla birlikte aile hekimleri gerektiğinde hastanelere sevk etmektedir. Sağlık ocakları ise koruyucu sağllk hizmeti sunumu görevini üstlenmektedir. Bireyler istedikleri aile hekimine giderek rahatsızlık durumunda önce buraya başvurmak durumundadır. Hasta direk hastaneye başvuramamakta ve mutlaka aile hekimi (general practitioner) sevki gerekmektedir. Aile hekimleri kapı doktoru, genel pratisyen gibi isimler almakta, kendi evlerinin bir odasında ya da sağlık ocağı içinde kiraladıkları bir odada hizmetlerini sunmaktadır (Aksakoğlu ve Giray, 2006, s.3).

NHS, İngiltere'de "normal olarak ikamet eden" herkese koruyucu hekimlik, birinci basamak ve hastane hizmetleri sunmaktadır. Kamu tarafından finanse edilen sağlık hizmetlerinin sorumluluğu parlamentoya karşı da sorumlu olan Sağlık Bakanına aittir. Sağlık Bakanlığı, NHS, halk sağlığı, yetişkinlere yönelik sosyal bakım ve diğer ilgili alanlar üzerine politika belirlemekten sorumlu merkezi hükümet organıdır. Bakanlığın ana rolü, hükümetin İngiltere'deki nüfusun sağlığının iyileştirilmesine destek olmak ve genel sağlık politikası ile stratejisini belirlemek aynı zamanda mevzuat ve yönetmelikler çıkarmaktır (Boyle, 2011, s. xxii). 
NHS'nin üç temel ilkesi vardır. Bunlar: herkesi kapsaması, ücretsiz olması ve vergilerden finanse edilmesidir. Bu üç temel ilke doğrultusunda sistem işlemiştir. NHS, aşağıda sayılan hedeflerle faaliyet göstermiştir (Vall-Spinosa,1991, s.1566):

1. Ödeme kabiliyetine bakılmaksızın herkese sağlık hizmeti sunulmasi,

2. Hastanelerin kamulaştırılması,

3. Hastane doktorlarını maaşlı çalışanlar haline getirilmesi ancak aynı zamanda NHS hastanelerinde ve özel bürolarda özel olarak pratik yapmalarının sağlanması,

4. Genel pratisyenlerin bağımsız yükleniciler olmasına izin verilmesi,

5. Vatandaşların istedikleri takdirde özel sigorta almalarına izin verilmesi,

6. Doktorun klinik kararını etkilememesi için sağlık bakımını hastaların gelirine bağlamaktan kaçınılması.

1950-1960 yıllarında NHS' de sağlık hizmetlerinin neredeyse tamamı kamu tarafından finanse edildiğinde bile kamu hizmetlerinde düzenli sorunlar devam etmiş, 1950'li yıllarda genel pratisyen hekiminin durumu kötüleşmiş, kamu hizmeti altında sunulan bu karmaşanın birden çözülmesi daha da zor hale gelmiştir (Greener, 2015, s.688). Kamulaştırmanın ağırlıkta olduğu bir sağlık endüstrisi yaratan 1950'lilerin çeşitli hükümetleri, hizmetlerin nasıl verimli bir şekilde yönetilebileceğine eleştirel bakmaya başlamış, hastaneleri "komuta ve kontrol" yönetim tarzıyla yönetmeye çalışmıştır. Bu yönetim tarzı savaş döneminin etkisiyle, merkezi talimatlar merkezi hükümetten yerel hastane kurullarına ve bir dizi otoriteye yansımaktadır (Greengross et al., 1999, s. 7$8)$.

1960'lı yıllarda ise yeni binalarda ve teknolojide gelişmeler baş göstermiştir. Sağlık planlaması sermaye planları üzerinde yoğunlaşmış, "İngiltere ve Galler için Hastane Planı" ile on dört yeni Bölge Hastanesi kurulmuştur. Bu İlçe Genel Hastanesi kavramının altında, yerel nüfusa kapsamlı, iyi organize edilmiş bir şekilde hizmet vermenin amacı vardır, ancak sadece uzman bakıma ihtiyaç duyan insanların, kalp hastalıkları gibi uzmanlık alanlarının bulunduğu Bölgesel Hastanelere gitmeleri gerekmiştir (Greengross et al., 1999, s.7-8). 
1970'lerde sağlık yönetiminde "kurumsal" yaklaşımlar bakış açısı hâkim olmuş, nüfus esaslı bir finans sistemi devam etmiştir. Ancak yönetim ve personel arasındaki ilişkiler, güçlü olan sendikalar tarafından daha da kötüleşmiştir (Greengross et al., 1999, et al 7-8). 1974 yılına gelindiğinde, üç temel bakım alanının ayrıştırılmasından kaynaklanan sorunlar üzerine endişeler artmıştır, bu nedenle yerel yönetimlerin her üç bakım alanını da desteklemesine izin veren ciddi bir yeniden düzenleme girişimi olmuştur.

\section{Sonrası Dönemde Sağlık Sisteminin Genel Özellikleri ve Sağlık Poli- tikaları}

Margaret Thatcher'ın Muhafazakâr Hükümetinin 1979 yılında göreve gelmesiyle birlikte NHS, piyasa güçleri tarafından tehdit edilmiştir. Thatcher başa geçtiğinde Washington Konsensüsü çerçevesinde neoliberal pazarı yaymak için ABD başkanı Ronald Reagan ile ilişki kurmuştur. Görev süresinin bitimine yakın ise sağlık hizmetlerine odaklanmış, ABD’li ekonomist Alan Enthoven'ı getirerek (1985), onun yaklaşımı olan “iç pazar" anlayışını sağlık hizmetinde rekabeti arttırmanın gerekliliğini öne sürmüştür. Aslında başlarda NHS'nin merkezi yapısına müdahale etme amacı taşımadan piyasa güçleri sisteme alınmak istense de bazıları Thatcher'ın asıl hedefinin özelleştirmek olduğunu öne sürmüştür (Mooney, Çev. Terzi, 2014, s.110-111).

Birleşik Krallık başbakanı olan Margaret Thatcher (1925-2013), 19711989 yılları arasında ABD Başkanı Ronald Reagan ile olan resmi olmayan deniz aşırı ittifakı, bugün etkili olan uluslararası bir neoliberal politika gündeminin geliştirilmesinde önemli bir rol oynamıştır. 1970'lerde İngiltere sosyal demokrasisi üzerine yaptığı eleştiri ve finansal düzensizleşme, ticaret liberalizasyonu ve kamu mallarının ve hizmetlerinin özelleştirilmesi gibi temel neoliberal stratejilerin benimsenmesi "Thatcherism" olarak etiketlemesine neden olmuştur. Thatcher'in politikaları, sosyo-ekonomik ve sağlık eşitsizliklerine bağlanmış, bu konuların göz ardı edildiği öne sürülmüştür (Scott-Samuel, 2014, s.54).

Thatcher döneminde, yönetim sistemi yeniden yapılandırılmış ve 1990 yılında hastane bakımını yöneten, bağımsız tröstler kuran Ulusal Sağlık Sistemi ve Toplum Bakımı Yasası yürürlüğe girmiştir (Chang et al., 2011). 
Hastaneler Sağlık Bakanlığı'ndan doğrudan sorumlu NHS tröstleri olarak örgütlenmiştir. Vakıf tröstleri yarı idari, kendi kendini yöneten kamu tröstleri olarak kurulmuştur (Boyle, 2008, s.1).

Toplum Bakımı Yasası'ndan önce NHS sistemi tek merkezli yapısal bürokrasi ile yönetilmiştir, ancak iç pazarın oluşmasıyla hizmet sağlayıcılardan hizmet satın almak için aile hekimleri ve sağlık otoritelerine bütçe verilmeye başlanmıştır. İç piyasadaki sağlık kurumları ise tröstlere dönüşmüştür (Sargutan, 2010,s.159). Özellikle hastanelerin kuruluş vakfı olan tröstlere dönüştürülmesi, özerkleşmeyi arttırmış, artık Sağlık Bakanlığı'na değil, yeni bir sağlık piyasası düzenleme birimine karşı sorumlu olacaklardır. Bu kuruluş vakıfları, ticari faaliyetler içeren yollarla veya özel şirketlerle ticari girişim ortaklıkları kurarak maddi olarak kazanç sağlayabilmiş, özel finans piyasasından kredi temin elde edebilmiştir. Sonuçta NHS'ye bağlı vakıfların birer işletme statüsüne dönüşmesi doğaldır (Hermann, 2010, s.151).

Birleşik Krallıktaki sağlık hizmetlerinin organizasyonu 1990'dan beri önemli değişiklikler geçirmiştir. NHS'nin başlıca reformları 1991 başlarında başlatılmış, odak noktası iç pazar olmuştur. 1996 yılına kadar reformlar tamamen uygulansa da 1997 yılındaki hükümet değişikliği de dâhil olmak üzere devam eden değişiklikler sebebiyle reformların tam etkisi görülmemiştir. Teorik olarak hizmet sunucuları arasında sağlayıcı pazarlarının daha fazla verim sağlaması beklense de pratikte bunlar daha yüksek işlem maliyetlerinden dolayı istenilen seviyede olmamıştır. Bu NHS reformunun birincil amacı, tüketicinin yaşadığı sağlık hizmetlerinin kalitesini iyileştirmek olsa da yeni sistemde doğrudan kontrol düşük seviyede olmuştur. Sağlık Bakanlığı ulusal standartları yaymaya devam etmiş, kilit akademik kurumlar, uluslararası bir eğilimle etkili ve uygun sağlık hizmeti uygulama kılavuzlarının geliştirilmesinde artan bir rol oynamıştır (Jakubowski and Busse, 1998, s.124-125).

Sağlık hizmetlerinin gittikçe parçalanması, fiyatlandırma sistemine geçilmesi, taşeronlaşma ve kamu-özel sektör ortaklıklarına giden yolu açmasına neden olmuştur. Önce temizlik, yemekhane, çamaşır gibi ikincil hizmetlerden başlayan taşeronlaşma muhasebe, bilgi teknolojileri gibi komplike işlere de yansımışır. Britanya hükümeti, kalça ameliyatı gibi acil müdahale gerektirmeyen bazı standart cerrahi işlemler için yeni tedavi merkezleri açmıştır. Üstün uzmanlaşma ve acil vakalarla hizmet 
kesintilerinin olmamasından verimliliğin artacağını, bazı cerrahi işlemlerin hastaların kişisel tercihi olması sebebiyle bekleme sürelerinin de kısalacağını öngörmüşlerdir. Bu kapsamda ilk tedavi merkezleri NHS tarafından işletilmiş, 2002' de hükümet özel şirketleri “bağımsız sektör"ü yani kâr amacı güden şirketleri sisteme davet etmiştir. Bu görüşe göre özel sektör kapasite yaratacak, hizmetlerini de "rekabet gücü sunan birim maliyetlerle sunabilecek, kısacası NHS'den daha uygun maliyet sağlayabilecektir. 2007 Temmuz itibari ile 24 bağımsız sektör tedavi merkezi hizmet sunmuştur (Player and Leys, 2008; Akt. Hermann, 2010, s.155).

\section{Ulusal Sağlık Sisteminde Son Dönem Gelişmeler}

Muhafazakârlar ve Liberal Demokratlar koalisyonu 2010'da iktidara gelmesiyle Yeni İngiliz Sistemi devreye girmiştir. Her ne kadar başlarda tepeden inme kararlar alınmayacağı öne sürülse de, NHS koalisyonla yeniden bir yapılanmaya daha gitmiştir. Aşağıdaki şekilde gösterilen yeni İngiliz Sağlık Sistemi, hizmetin neredeyse her düzeyini etkileyen ve yukarıdan aşağıya inen radikal ve önemli revizyonunu yansıtmaktadır (Peckham, 2014, s.156)

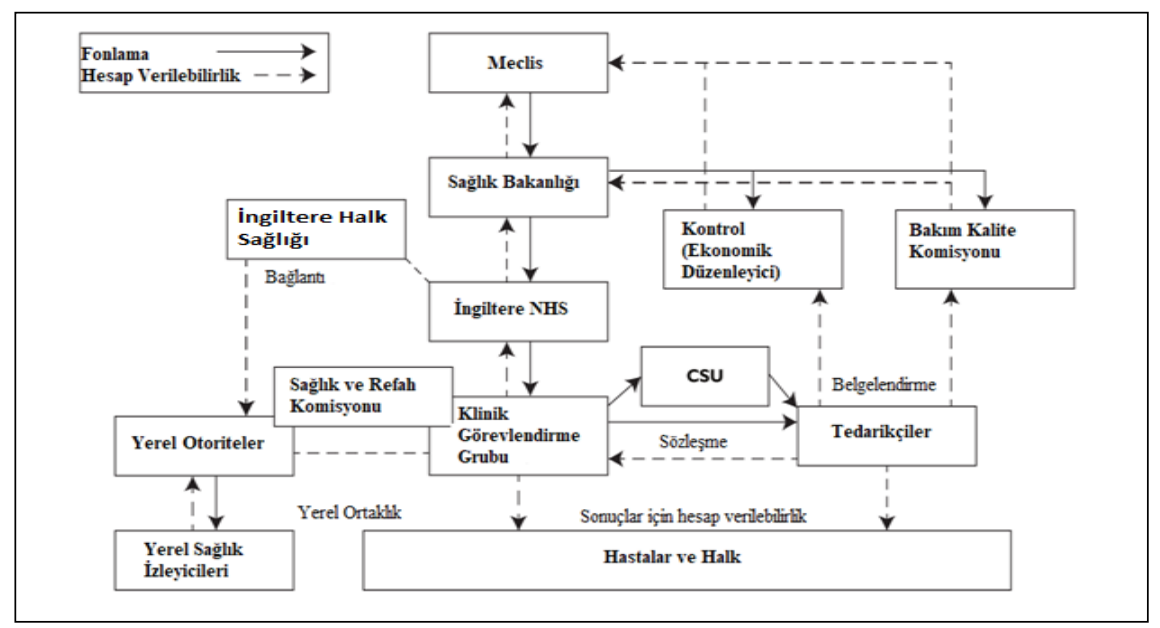

Şekil 1: Nisan 2013 Sonrası Süreçte İngiltere'de Ulusal Sağlık Sistemi(NHS)(Peckham,2014) 
Nisan 2013 öncesinde, birincil bakım birimleri (PCT) NHS bütçesinin \% 85'inden sorumludur. Belli bir coğrafi nüfus içinde birincil ve ikinci basamak sağlık hizmetlerinin çoğunu vermekle görevlidirler, halk sağlığ1 hizmetlerini yürütmektedirler. Nisan ayından (2013) itibaren ise, tüm sağlık sektörlerinde hiç bir kuruluşun ve halk sağlığının bütçelerinin olmadığ1 görülmektedir. Coğrafi nüfus ilkesi korunmakla birlikte, klinik görevlendirme grupları (CCGs) genel sağlık hizmetleri veya bazı uzman hizmetleri için sözleşme yapmamakta ve halk sağlığı hizmetleri görevini üstlenmemektedir. Burada sorumluluk İngiltere Halk Sağlı̆̆ Kurumu ve yerel yönetimler tarafından yerine getirilmektedir. 2010 yılında tanıtılan ve 2012/13 y1lında yürürlüğe giren İngiliz NHS'sindeki değişiklikler üç ana hedefe sahiptir (Peckham, 2014, s.157):

- Klinisyenler tarafından yönlendirilen, sürekli örgütsel reformu destekleyen, kendi kendine devam eden bir teşvik seti oluşturmak;

- Daha fazla özerkliğe izin vermek, ancak seçici bir temelde, merkezi olarak belirlenen ölçütlere göre performansın merkezi değerlendirmesine bağlı olmak;

- Yerel provizyon için çoğulcu bir model oluşturmaktır.

- Kisacası Cameron'un (2010) başa geçmesiyle birlikte NHS yeniden örgütlenmeye çalışılmıştır. David Cameron, 2010'da "NHS'yi değil, harcamalardaki açı̆̆ı kapatmaya" söz vermiştir. Ancak koalisyon politikaları, sağlı üzerinde de aşağıda betimlenen şekilde bir etki yaratmıştır (Vizard and Obolenskaya, 2015, s.1):

- Koalisyon sağlık harcamalarını diğer harcama alanlarına göre koruyacağını belirtirken, reel sağlık harcamalarındaki büyüme önceki hükümet standartlarına göre düşük kalmıştır. Yıllık ortalama büyüme oranları, artan ihtiyaç ve talebe yant olarak, NHS bakımını sürdürmek ve genişletmek için gerekli görülen oranların oldukça gerisinde kalmıştır.

- Tahminlere göre hizmetlere yönelik artan baskılar verimliliğin artması ve finansman artışları ile dengelenmedikçe 2020/21 yılına kadar 30 milyar sterlin kadar NHS'de büyük bir finansman açığı olacaktır.

- Âdemi merkeziyet, rekabet ve sonuçlar üzerinde duran başlıca sağlık reformları gerçekleştirilmiştir. Bunlar, İngiltere'de sağlık hizmetlerinin, yönetiminin politika alanını değiştirmiştir. 
İngiltere'de sağlık hizmetlerine dair politik sorumluluk ve hesap verebilirlik genel çerçevede değişmiştir.

- Mid-Staffordshire NHS Vakfı Tröst Halk Soruşturması'nı takiben, minimum bakım standartları, muayene ve kalite düzenlemeleri bakımından revize edilmiştir ve güçlenmiştir. Göstergeler, sağlık hizmeti erişimi ve kalitesinde artan baskıyı ortaya koymaktadır. Bunlar, aile hekimlerine hasta erişimi, kaza ve acil servisler ve kanser bakımıyla ilgili başlıklarda değerlendirilmiştir.

- NHS ile halkın memnuniyeti 2010'da ulaşılan zirve oranından oldukça düşük kalmıştır. İngiltere'nin OECD "uluslararası lig tabloları" sıralaması, kadınların yaşam beklentileri ve bebek ölümleri gibi bazı sağlık sonuçları alt sıralarda kalmış, 2007 ekonomik krizinden sonra intihar ve zihinsel sağlık sorunları yaygınlaşmıştır.

- Sağlık eşitsizlikleri artmış, İngiltere'nin en fakir ve en zengin bölgelerinde yaşayan erkekler arasındaki ortalama yaşam beklentisi arasındaki fark dokuz yıla ve kadınlar için altı yıla çıkmıştır.

Koalisyon Anlaşmasında Muhafazakârlar ve Liberal Demokratlar, parlamentonun her yılında kamu harcamalarını artırma sözü vermişlerdir. Hükümet Programı, kullanım noktasında ücretsiz olan ve ödeme kabiliyeti olmayan kişilerin ihtiyacına dayalı bir NHS'yi korumayı taahhüt etmiştir. Sağlık reformlarının etkisinin genel değerlendirmesi açısından orta vadede, örgütsel âdemi merkeziyetçilik, artan rekabet, sonuç vurgulaması, yeni denetim rejimleri, sağlık eşitsizliklerini gidermek için verilen görevler ve halk sağlığ için yeni düzenlemelerle sağlık hizmetlerine erişim konusunda farklı faktörlerin etkisini belirlemek için bir kanıt temeline ihtiyaç duyulacaktır. Ayrıca sağlık çıktılarını iyileştirmeye ve farklı sosyal gruplar arasındaki sağlık eşitsizliklerine değinilmesine odaklanılmaktadır (Vizard and Obolenskaya, 2015, s.2-7).

1999'daki politik devrimden bu yana, Birleşik Krallıktaki dört ülkenin (Birleşik Krallık) sağlık sistemleri arasında giderek artan bir politika farklılığı vardır. Bir takım göstergelerde performans artsa da 2010'dan bu yana bekleme süreleri uzamıştır. Diz veya kalça protezleri gibi bazı işlemler için bekleme sıralarında çarpıcı artışlar olmuştur, örneğin, 2012/13 yılında, Galler'deki hastalar kalça veya diz protezi için ortalama 170 gün, İngiltere ve İskoçya'da yaklaşık 70 gün beklemişlerdir. Diğer Birleşik Krallık Ülkelerine göre (Galler, İskoçya, İrlanda), İngiltere'de hemşire 
personel düzeyleri diğer üç ülkeden daha düşük olmuştur. Ayrıca 2006'dan bu yana İngiltere'de örgütsel kargaşa daha da artmıştır. Bunun sebebi ise İngiltere'deki temelli rekabet ve bireysel hasta seçiminin politika vurgusudur. Çeşitli tedarikçiler arasındaki rekabet 2012 Sağlık ve Sosyal Bakım Yasası daha da teşvik edilmiştir (Bevan vd., 2014, s.1-5-6).

\section{Avrupa Birliği ve NHS}

Son yıllardaki İngiliz sağlık politikalarındaki değişimler, Theresa May hükümeti ile bir başka boyuta ulaşmıştır. Çünkü Başbakan May, 2017 yılı itibariyle 23 Haziran 2016' da yapılan referandumdan yüzde 52 oy sonucu ortaya çıkan Avrupa Birliği'nden (AB) ayrılma sürecini (Brexit) başlatmış bulunmaktadır. Kamuoyunda hemen her kesim tarafından tartışılan Brexit'in NHS için daha kötü sonuçları beraberinde getirebileceği görüşü sıklıkla dillendirilmektedir.

İngiltere'nin Avrupa Birliği'nden ayrılması sağlık hizmetleri finansmanı, sağlık işgücü, İngiliz vatandaşlarının Avrupa ülkelerindeki sağlık hizmetlerine erişimi konularında ciddi değişiklikler doğuracaktır. NHS vergilerle finanse edildiğinden ekonomideki değişimlerden doğrudan etkilenmektedir. $A B^{\prime}$ den ayrılış, ülke için genel olarak kamu hizmetlerinin finansmanı için daha az kaynak anlamına gelmektedir. Hâlihazırda İngiltere' de pek çok $A B$ vatandaşı sağlık çalışanı bulunmaktadır ve bu kişiler şimdiden ülkelerine dönmeye başlamışlardır. Bunun dışında, AB vatandaşlarının $A B$ ülkelerinde sağlık hizmetlerinden ücretsiz olarak yararlanma hakkından İngiltere vatandaşları mahrum kalacaktır.

Ulusal Denetim Ofisi'nin (NAO, 2018, s.7) raporuna göre NHS toplam geliri olan 80.552 milyon $£$ 'a karşı 791 milyon $£$ ' l1k bir açık vermektedir (2018 verisi). Her sağlık sisteminde olduğu gibi İngiltere'de de finansal sürdürebilirlik, kişilerin sağlık hizmetlerinden en iyi şekilde faydalanması, kaynak verimliliği gibi konularda endişeler vardır. Ancak durum farklı bir boyuta gelmiştir. OECD'nin “Brexit'in Ekonomik Sonuçları: Vergi Kararı" adlı raporunda Avrupa Birliği üyeliğinin, Birleşik Krallığı'n ekonomik refahına katkıda bulunduğu, en iyimser senaryolarda bile Brexit sürecinin hem İngiltere'nin hem de diğer Avrupa ülkelerinin ekonomisinde negatif anlamda bir şok etkisi yaratacağı öne sürülmüştür (Oecd Economic Policy Paper, 2016). 
EHIC (AVRUPA Sağlık Sigortası Kartı) kısa süreli ziyaretçiler için devlet tarafından sağlanan sağlık hizmetlerine erişimini, S1 programı ise emekliler gibi yurtdışında yaşayan bireylerin sağlık ve bakım hizmetlerine erişimini sağlamaktadır. 2017 verisine göre İngiltere'de 27 milyon kişi EHIC sahibidir ve AB'de yaşayan 190.000 İngiltere emeklisi S1 planına kayıtlıdır (http://data.parliament.uk). AB ve İngiltere hükümeti arasında devam eden müzakerelerin nihai sonucuna bağlı olarak Brexit sonrası, Avrupa ülkelerince verilen sağlık hizmetlerine erişimi sağlayan EHIC (Avrupa Sağlık Sigortası Kartı) hakkını kaybedebilir. Bu durumda Avrupa Birliği ülkelerinde tedavi amaçlı bulunan Birleşik Krallık vatandaşlarının ülkelerine dönmesi gerekebilir, bu da yılda $£ 500 \mathrm{~m}$ kadar ek maliyetle NHS üzerinde baskı yaratacaktır. Birleşik Krallık ve $A B$ vatandaşları için karşılıklı sağlık bakımı düzenlemelerinin devamı için müzakerelerde ön planda tutulması gerekmektedir (British Medical Association, 2018, s.2).

Fahy vd.'ne göre (2018, s.13) Brexit sürecinin İngiltere sağlık sistemi üzerinde etkisi olacağ 3 tür senaryo öne sürülmektedir; "yumuşak Brexit", “zor Brexit", "başarısız Brexit". Yumuşak Brexit'e göre yasal olarak, Birleşik Krallık'ta AB'nin Adalet Divanı'na (ECJ) erişim olmadan $\mathrm{da}, \mathrm{AB}$ yasalarının çoğunun uygulanmaya devam edeceğini içerir. Böylece yerel yasalar mevcut olan $\mathrm{AB}$ yasalarına uyarlanacaktır. Ancak bunun uygulamada bazı sorunlar doğuracağı öne sürülmektedir. Zor Brexit'de, AB ile Kanada arasındaki yakın zamanda imzalanan serbest ticaret anlaşmasına (FTA) benzeyen çok çeşitli AB-İngiltere serbest ticaret anlaşmasını içerir. Başarısız Brexit senaryosuna göre ise, Birleşik Krallık aniden ek tarifelerle karşı karşıya kalacak $A B$ ile ve şu anda $A B$ ile serbest ticaret anlaşmaları altında ticaret yapılan diğer ülkelerle olan her türlü mal kotalarına tabi olacaktır.

Brexit'in sağlık üzerindeki etkileri, DSÖ Sağlık Sistemi Çerçevesinde tanımlandığı gibi bir sağlık sisteminin her bir "yapı bloğuna" dokunacaktır. (Fahy et al, 2018, s.10). Bu çerçevede sağlık işgücü AB vatandaşlarını da kapsaması nedeniyle çarpıcı şekilde etkilenecektir. Brexit, sağlık çalışanlarına İngiltere'yi yasal hakları ve ailelerinin hakları açısından AB'nin diğer bölgelerinden daha az cazip hale getirebilir. Bir diğer etki finansman üzerinde olacaktır. Çünkü karşılıklı sağlık düzenlemeleri sona erdiğinde hastalar yurtdışındayken teminat kaybedecektir. Brexit'in NHS 
sermaye finansmanı üzerinde de etkileri vardır. Ek olarak, $\mathrm{AB}$ yasalarının ilaç ruhsatlarının hemen her yönünü yönetmektedir. Ne kadar az görünse de, ayn derecede önemli olan, tıbbi cihazlar ve radyoizotoplar dahil olmak üzere diğer tıbbi ürünler üzerinde de etkili olacaktır (Fahy et al, 2018, s. 3-7).

\section{Sonuç ve Değerlendirme}

Birleşik Krallık ülkelerinden olan İngiltere, vergilerle finanse edilen ücretsiz sağlık hizmeti sunumuyla tüm nüfusu kapsamayı hedefleyen politikalarla hareket etmektedir. İkinci Dünya Savaşı'ndan sonra Beveridge raporu ile ücretsiz, herkesi kapsayan ve vergilerle finanse edilen sağlık sistemi tartışılmaya başlanmıştır. Merkezi yönetim tarafından halk sağlığı hizmeti sunucuları ortaya çıkmış, böylece tüm nüfus kapsama alanına alınmaya çalışılmıştır.

Bu kapsamda 1948 yılında kurulan NHS (Ulusal Sağlık Sistemi), kamu sağlığından sorumlu kurum olarak hizmet sunumu sorumluluğunu üstlenmiştir. 19. yüzyılda hayırseverler aracılı̆̆ıyla sunulan sağlık bakım hizmetleri, merkezi vergilerin finansman olarak kullanılmasıyla birlikte NHS ile devam etmiştir. NHS, kapsama alanı tüm vatandaş olan, devlet eliyle yürütülen ve sevk zincirinin sağlıklı şekilde yürütülmesi amaçlanan bir sağlık sitemi olarak ortaya çıkmıştır. Sistemin esası herkesi kapsaması, vergilerle finanse edilmesi ve ücretsiz olması olmak üzere üç temel ilkeye dayandırılmıştır.

NHS, siyasal iktidarların kendisine has politikalarıyla zaman içerisinde değişim yaşamıştır. 1950-1960'lı yıllarda tamamen kamu tarafından verilen sağlık hizmeti kapsamıla yerel hastaneler yapılanması söz konusu olmuş ve uzmanlık gerektiren sağlık hizmet talepleri için ise vatandaşlar merkezi hastanelere (bölge hastaneleri) gitmek durumunda kalmıştır. 1979'da Margaret Thatcher'ın Muhafazakâr Hükümetinin yılında göreve gelmesiyle birlikte ise neoliberalizm odaklı politikalar tartışılmaya başlanmış ve her ne kadar merkezi yapıya müdahale olmasa da özelleştirme uygulamaları gündeme gelmiştir. Thatcher (1993, s.676) özelleştirmeyi sadece ekonomik performansın yükselmesi için bir araç olarak görmemiştir. Kitabında özelleştirme için "sosyalizmin aşındırıcı ve 
yozlaşan etkilerini tersine çevirmenin temel araçlarından biridir" demiştir.

Daha sonra ise Muhafazakârlar ve Liberal Demokratlar koalisyonu 2010 'da iktidara gelmesiyle NHS yeni bir değişim daha yaşamış, yapısal değişimden sağlık harcamaları, memnuniyet oranı da yukarıda bahsedildiği gibi olumsuz etkilenmiştir.

Son olarak Lizbon Anlaşmasının 50. maddesi dayanağıyla Avrupa Birliği'nden ayrılma sürecini (Brexit) başlatan İngiltere Başbakanı Theresa May, sağlık sisteminde de bir yeni bir değişime daha neden olmuştur. Bazı görüşlere göre Brexit'in sağllk sistemi üzerinde olumsuz etkilerinin olacağ 1 öngörülmekte olup bu bağlamda, araştırma, tedavi gibi alanlarda finansman ve destek kaybına neden olacağı düşünülmektedir. 
EXTENDED ABSTRACT

\title{
England Health Policies from Past to Present: A Current Perspective Focused on the National Health System
}

\author{
Erdal Eke - Merve Kişi \\ Süleyman Demirel University
}

The England Health System is a tax-based Beveridge-type health system. England, under the leadership of Sir William Beveridge, returned to social restructuring after World War II. After Beveridge's report, the UK Health System evolved into a national health system (NHS, National Health System). The NHS has emerged as a public health system for all, providing free health care and funded from central taxes. The financing known as Beveridge-type health systems finans is a tax-based health system and consists of 3 steps. In the system aiming at an effective referral chain, family physicians play the role of door doctors, and the person has to register with the family physician of their choice and apply here first. The family physician makes referrals to the 2nd and 3rd level hospitals where necessary. Family physicians and public hospitals are particularly important in terms of service delivery. All residents of the UK are covered by the National Health System. The Minister of Health, who is responsible for publicly funded health services, is also responsible to the parlemont. The Ministry of Healthis the central governmental body responsible for policymaking on public health, NHS, adult social care and other related areas. The NHS has three basic principles. These include: covering everyone, being free and being tax-financed. Since the establishment of the NHS, the England Health System has undergone some changes with the various policies of various governments. The most striking of these changes was the actions of Margaret Thatcher, who transformed her name into a movement. With the advent of neoliberalism with President Thatcher in the late 1970s, privatizations took place in the England health system, which is a purely national system. Accordingly, with the establishment of the 
Conservative Government of Margaret Thatcher in 1979, he proposed the necessity of increasing the competition in health care with the "internal market" approach. While the adoption of neoliberal strategies is basically called "Thatcherism", some changes have taken place in the NHS and the management system has been restructured. In 1990, the National Health System and Community Care Act, which governs hospital care and establishes independent trusts, came into force. Hospitals are organized as NHS trusts. Foundation trusts were established as semi-administrative, self-governing public trusts. Particularly with the transformation of hospitals into trusts, the increase in autonomy was no longer the responsibility of the Ministry of Health but of a new health market regulatory unit. The fragmentation of health services, the introduction of a pricing system, led to subcontracting and public-private partnerships. Subcontracting first started from secondary services such as cleaning, cafeteria and laundry, and then reflected on complicated tasks such as accounting and information technologies. When the Conservative and Liberal Democrats coalition came to power in 2010, the New British System came into play and a new restructuring was initiated. Although the exact desired goals could not be achieved, with the arrival of the Theresa May government, the England Health System has reached another dimension. As of 2017, Prime Minister May launched the process of leaving the European Union (EU) (Brexit), which was the result of a 52 percent vote in the referendum held on 23 June 2016. It is often expressed that Brexit, which is discussed by almost all the public opinion, can lead to worse results for the NHS.

Brexit's health impacts will touch each "building block inin of a health system. In this context, the health workforce will be strikingly affected as it includes EU citizens. Another impact will be on financing. Because when the mutual health regulations expire, patients will lose collateral while abroad. In this article, the changes in the UK Health System are discussed gradually and the opinions in the literature are tried to be included. The aim of the study is to describe UK health policies before and after the National Health System. According to the findings of the study, it is understood that the UK Health System has undergone functional changes as a result of various policies by various governments. 


\section{Kaynakça / References}

Aksakoğlu, G. ve Giray, H. (2006). Birleşik Krallık'ta ulusal sağlık hizmetinin öyküsü, Toplum ve Hekim TTB Yayını, 21, 335-343.

Ateş, M. (2011). Sağlık sistemleri, İstanbul:Gerekli Kitap Yayınları .

Bevan, G., Karanikolos, M., Exley, J., Nolte, E., Connolly, S., ve Mays, N. (2014). The four health systems of the United Kingdom: How do they compare? Summary Report. The Health Foundation.

Boyle, S. (2008). The health system in England. EUROHEALTH-LONDON, 14(1), 1-114.

Boyle, S. (2011). United Kingdom (England). health systems review. Copenhagen: WHO Regional Office for Europe. Health Syst Transit, 13(1), 1-486.

British Medical Association (2018). Brecit briefing reciprocal healthcare between the $U K$ and the $E U$, https://www.bma.org.uk/collectivevoice/influence/europe/brexit/bma-brexit-briefings/reciprocalhealthcare 20.04.2019 tarihinde adresinden erişildi.

Chang, J., Peysakhovich, F., Wang, W., ve Zhu, J. (2011). The UK health care system. The United Kingdom. 30.01.2019 tarihinde http://assets.ce.columbia.edu/pdf/actu/actu-uk.pdf adresinden erişildi.

Cylus, J., Richardson, E., Findley, L., Longley, M., O'Neill, C., ve Steel, D. (2015). United Kingdom: Health system review. Health systems in transition, 17(5), 1-126.

D., Gönül (2009). Birleşik Krallık Sağlık Sistemi,19.11.2017 tarihinde http://halksagligiokulu.org/anasayfa/components/com_booklibrary/ebooks/nhs_kitap_0210.pdf, adresinden erişildi.

Fahy, N., Hervey, T., Greer, S., Jarman, H., Stuckler, D., Galsworthy, M., ve McKee, M. (2019). How will Brexit affect health services in the UK? An updated evaluation. The Lancet, 393(10174), 1-10.

Greener, I. (2015). Wolves and big yellow taxis: How would be know if the nhs is at death's door?: Comment on who killed the english national health service?. International Journal Of Health Policy And Management, 4(10), 687-689. 
Greengross, P., Grant, K. ve Collini, E. (1999). The UK national health service, DFID Health Systems Resource Centre, 02.04.2019 tarihinde http://www.heart-resources.org/wp-content/uploads/2012/10/The-history-and-development-of-the-UK-NHS.pdf adresinden erişildi.

Hermann, C. (2010). Kapitalizmde sağlık, sağllksızlık semptomları, L. Panitch ve C. Leys (Eds.) , U. Haskan (Çev.), (2. Bsm), London:Merlin Press.

Hitiris, T.(1997) Health care expenditure and integration in the countries of the European Union, Applied Economics, 29(1), 1-6. 19.11.2017 tarihinde http://www.who.int/topics/health_systems/en/ adresinden erişildi.

Jakubowski, E. ve Busse, R. (1998). Health Care Systems in the EU [: A Comparative Study, European Parliament, 02.04.2019 tarihinde http://www.europarl.europa.eu/workingpapers/saco/pdf/101 _en.pdf adresinden erişildi.

Lameire, N., Joffe, P. and Wiedemann, M., (1999). Healthcare systemsan international review: An overview, Nephrology Dialysis Transplantation, 14(6), 3-9.

Light, D. W. (2003). Universal health care: Lessons from the British experience, American Journal of Public Health, 93(1), 25-30.

Mooney, G. (2012). Ulusların sağlığı yeni bir ekonomi politiğe doğru,.C. Terzi (Çev.), (1. Bsm), İstanbul: Yordam Kitap Basın ve Yayın.

National Audit Office (2018). Sustainability and transformation in the NHS, 30.01.2019 tarihinde https://www.nao.org.uk/wp-content/uploads/2018/01/Sustainability-and-transformation-in-theNHS.pdf, adresinden erişildi.

OECD (2016), Economic Policy Paper (NO:16), The Economic Consequences Of Brexit: A Taxing Decision, 30.01.2019 tarihinde,https://www.oecd-ilibrary.org/docserver/5jm0lsvdkf6ken.pdf?expires $=1532865541 \&$ id=id\&accname $=$ guest\&checksum=A66280D07F6BBBBA24DECF0069A3207F adresinden erişildi.

Peckham, S. (2014), Accountability in the UK healthcare system: An overview, Healthcare Policy, 10, 154-162. 
Sargutan, E. (2010). 84 Ülke ve Türkiye'nin Karşılaştırmalı Sağlık Sistemleri, http://www.sargutan.com/page17.html

Scott-Samuel, A., Bambra, C., Collins, C., Hunter, D. J., McCartney, G., ve Smith, K. (2014). The impact of Thatcherism on health and wellbeing in Britain. International Journal of Health Services, 44(1), 53-71.

Thane, P. (2009). Memorandum submitted to the House of Commons' Health Committee Inquiry: Social Care. 18.07.2018 tarihinde, http://www.historyandpolicy.org/docs/thane_social_care.pdf adresinden erişildi.

Thatcher, M. (1993). The downing street years, London: Harper Collins EBook.

The American College Of Healthcare Executives (Ache), Introduction to Health Policy, 17.07.2018 tarihinde, https://www.ache.org/pubs/Shi_Chapter1_2.pdf adresinden erişildi.

Vall-Spinosa, A., (1991). Lessons from London: the British are Reforming their national health service, American Journal of Public Health, 81(12), 1566-1570.

Vizard, P. and Obolenskaya P. (2015). The coalition's record on health: Policy, spending and outcomes 2010-2015, Social Policy in a Cold Climate Working Paper, 16, 1-160.

Yıldırım, H. H. ve Yıldırım T. (2011). Avrupa Birliği sağlık politikaları ve Türkiye, (2. Bsm), Ankara: İmaj Yayınevi.

\section{Kaynakça Bilgisi / Citation Information}

Eke, E. ve Kişi M. (2019). Geçmişten günümüze İngiltere sağlık politikaları: Ulusal sağlık sistemi odaklı güncel bir perspektif. OPUSUluslararası Toplum Araştırmaları Dergisi, 11(18), 2687-2707. DOI: 10.26466/opus.548218 